\title{
Research on the effect of diesel fuel injection parameters on the exhaust emissions in the turbocharged $\mathrm{CI}$ engine operating on propane
}

The article presents results of the studies on the charged, dual-fuel CI compression ignition engine fuelled with propane. The main goal of the studies was to fuel the engine so that the amount of energy provided with propane is possibly highest at the high efficiency, low emission of harmful exhaust constituents and proper combustion. As the studies conducted so far have shown, with the increase of energy from propane we observe crucial changes in the combustion process. As these changes may be a barrier in the further increase of energy, we decided to change the injection parameters of the diesel fuel. The changes introduced allowed for the 70\% energetic contribution of gas fuel at the subsequent elimination of unfavourable phenomena. The fuel injection was realized divided into two doses. Both proportions and angle at the beginning of the injection for both doses were variable. The angle at the beginning of injection for the first dose was changed in a wide range and depended on the value of charging pressure. The angle at the beginning of injection for the second dose was changed in a much narrower range, mainly due to very clear changes in the nature of combustion process. The studies have been conducted for three values of charging pressure, namely 200; 400 and 600 [mbar], and also for the naturally aspirated version. Study results have been presented in a form of regulation characteristics for the angle of the beginning of injection of the pilot dose for the chosen charging variants, as well as volume and angle of the beginning of injection for the main dose. The obtained results show that the content of exhaust constituents for the dual-fuel CI engine depends highly on assumed regulations of injection parameters of the fuel dose initiating the ignition, as well as engine charging pressure.

Key words: combustion engines, dual fuel, propane, alternative fuels, air pollution

\section{Introduction}

As numerous publications both domestic and foreign show, the idea of dual-fuel CI engine fuelling is attractive and keeps being developed [3]. This type of fuelling is considered to improve emitted exhaust constituents and to limit exploitation costs of engines fuelled in this way. This is the main concern of this article. What makes this fuelling type so attractive is the possibility of using cheaper fuels, available in the market. These may be both renewable fuels and those coming from crude oil refining, for instance mixture of propane and butane (LPG).

This fuel is in the field of interest of the companies adapting the CI engine due to their lower price as well as the problem of its distribution, which has already been solved $[1,2]$. Undoubtedly, the desirable feature of dualfuel supply is replacing a standard fuel oil with its cheaper substitute to the possibly highest extent and, what is more, using possibly easiest and cheapest methods of providing additional fuel without interference with the engine construction. Though, meeting the condition of maximising the contribution of additional fuel is not easy as there are limitations resulting mainly from the significant changes in the course of combustion process. These changes are the effect of supplying additional fuel along with the air in the cylinder filling cycle. Compressed gas is the mixture of fuel and air. The basic parameters of combustion process, and the same, exhaust constituents of the engine fuelled in this way highly depend on the content of this mixture. Fuel supply is most often realized with the use of mixer or injector, as it is the case in the installations supplying spark-ignition engines used already for years. It is though worth to mention that since these methods work for naturally aspirated sparkignition engines, they do not work so for charged diesel engines with valve coverage, as they considerably contribute to the escape of a part of the load what causes higher emission of hydrocarbons and hinders the efficiency of engine fuelled in this way. As the previous studies have shown [6] it is possible to supply additional fuel in such a way that we possibly limit the phenomenon of escaping of a part of the load. This method has also been applied during the studies, the results of which have been presented in this article. For the purpose of the study we used propane mainly due to the fact that we wanted to avoid mistakes stemming from the lack of knowledge in the content of LPG fuel version.

The main goal of the studies was to obtain comparable parameters characterizing work of a dual-fuel engine with the corresponding parameters of a standard engine with possibly high contribution of propane so that the biggest proportion of energy is supplied along with this fuel. Taking into account the fact that as a result of introducing of dual-fuel supply the course of combustion changes considerably we needed to shape this process so that the main goal is achieved. In order to achieve this goal we used the possibilities of modern supply system of common rail type. As these and further studies have shown, the way of releasing energy from propane greatly depends on the strategy of parameters selection for diesel fuel injection. It is crucial if an ignition-initiating dose is injected once or it is divided into pilot and main dose. The volume of the dose or doses initiating the ignition, as well as the angle of the beginning of injection are also significant. While introducing some changes in the abovementioned parameters of diesel fuel injection it is possible to flexibly shape the combustion process what allows for obtaining similar parameters of combustion process to those which characterize the work of engine fuelled in a standard way.

Being aware of the fact that a variable regulation of diesel fuel dose injection parameters corresponds to the change in exhaust constituents, the basic emitted constituents have 
been registered during the study. The registration of exhaust composition and pressure inside the cylinder allowed for the analysis of the influence of diesel fuel injection parameters on the combustion process in the engine fuelled in this way.

\section{Research object and measuring equipment used}

The studies have been conducted on the test bed of the company AVL, equipped with one-cylinder CI engine AVL 5402 adapted to dual-fuel supply. Propane in the gaseous phase has been supplied with the use of injector mounted in the intake manifold of the engine. Both injector mounting place and gas injection parameters have been selected so to limit the possibility of load escape in the moment of valve coverage. These parameters have been approved and determined on the basis of previously conducted studies [6].

General layout of the engine with dual-fuel supply has been presented in Fig. 1.

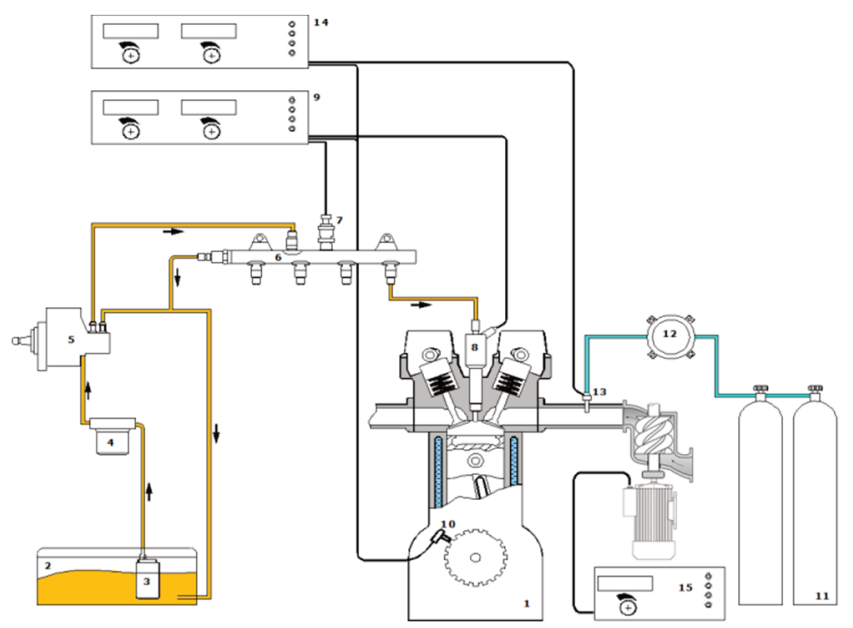

Fig. 1. General layout of dual-fuel system of CI engine supply: 1) dual-fuel engine, 2) diesel fuel tank, 3) electric fuel pump, 4) fuel filter, 5) highpressure fuel pump, 6) hopper, 7) fuel pressure sensor, 8) diesel fuel injector, 9) controller of common rail supply system, 10) crank shaft location and speed sensor, 11) gas container, 12) pressure regulator, 13) gas injector, 14) controller of gas supply system; 15) engine charging control system

Moreover, the test bed was equipped with the following measurement systems:

- eddy current brake AVL,

- indicating software (IndiCom),

- charging system (AVL boost - electrically powered compressor),

- exhaust analysis system (SESAM I 60),

- system of mass measurement of particle concentration (Micro Soot Sensor),

- system of mass measurement of flow rate of diesel oil used by the engine with temperature conditioning,

- system of mass measurement of flow rate of propane used by the engine (mini CORI-FLOW).

Fuel samples used for the studies came from one batch what aimed to avoid possible discrepancies concerning physical and chemical properties affecting the results of the studies.

An overall scheme of the test bed is presented in Fig. 2.

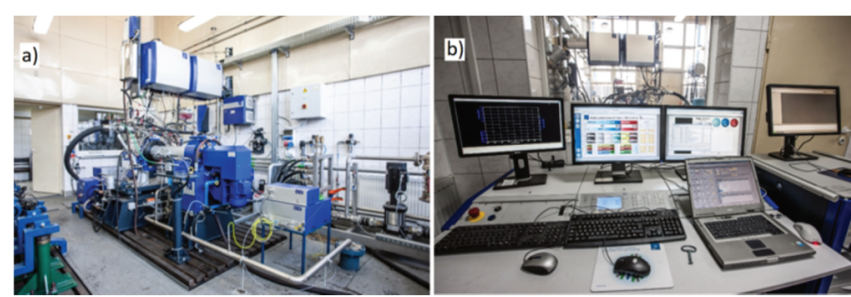

Fig. 2. AVL test bed: (a) general view of the test bed, (b) view of the control room

3. Research programme - assumptions and scope

It was decided to carry out the investigation in the following conditions:

- engine speed $\mathrm{n}=2400 \mathrm{rpm}$,

- three values of diesel fuel pilot dose have been selected: QI (2; 2.25; $2.5 \mathrm{mg})$,

- a wide range of variability in the injection advance of the diesel fuel pilot dose $\alpha \mathrm{I}$ has been chosen $\left(14^{\circ}-30^{\circ}\right.$ C.A. before TDC),

- three different values of the angle of the beginning of injection for diesel fuel main dose $\alpha$ II have been cho$\operatorname{sen}\left(5^{\circ}, 6^{\circ}, 7^{\circ}\right.$ C.A. before TDC),

- three values of charging pressure $\mathrm{p}$ have been adopted (600; 400 and 200 mbar) and uncharged version has been studied, (maximum adopted value of the charging pressure resulted from acceptable maximum combustion pressure, other values have been arbitrarily chosen),

- constant power contribution of propane at the level of $70 \%$ of energy supplied to the engine has been adopted,

- constant value of energy dose for diesel fuel at the level of $30 \%$ of energy supplied to the engine has been adopted (which means that the change of pilot dose does not affect the energy supplied with the diesel fuel),

- constant value of air-fuel ratio for all measuring points $\lambda=1.3$ has been adopted.

During realization of each measuring point the concentration of the basic exhaust constituents have been registered: nitrogen oxides $\mathrm{NO}_{\mathrm{x}}$, non-methane hydrocarbons NMHC, propane $\mathrm{C}_{3} \mathrm{H}_{8}$, and mass concentration of particulate matter PM.

\section{Study results}

\subsection{Variability characteristics of nitrogen oxides' content for different injection parameters of diesel fuel dose initiating ignition}

Limiting the emission of this exhaust constituent is still a challenge for diesel engine constructors. Due to its toxic properties it is necessary to look for solutions limiting its concentration. Research results presented below clearly indicate that there is a relation between the concentration of this constituent in the exhaust and adjustment of injection parameters of diesel fuel in the dual-fuel engine.

The results presented above allow to formulate the following conclusions:

- a growth of diesel fuel pilot dose QI is accompanied by the increase in $\mathrm{NO}_{\mathrm{x}}$ concentration,

- adjustment of injection advance of QI dose contributes to maximum dozen or so changes in $\mathrm{NO}_{\mathrm{x}}$ concentration for a charged engine and over thirty percent changes for an uncharged engine, delaying of injection advance of QII, 

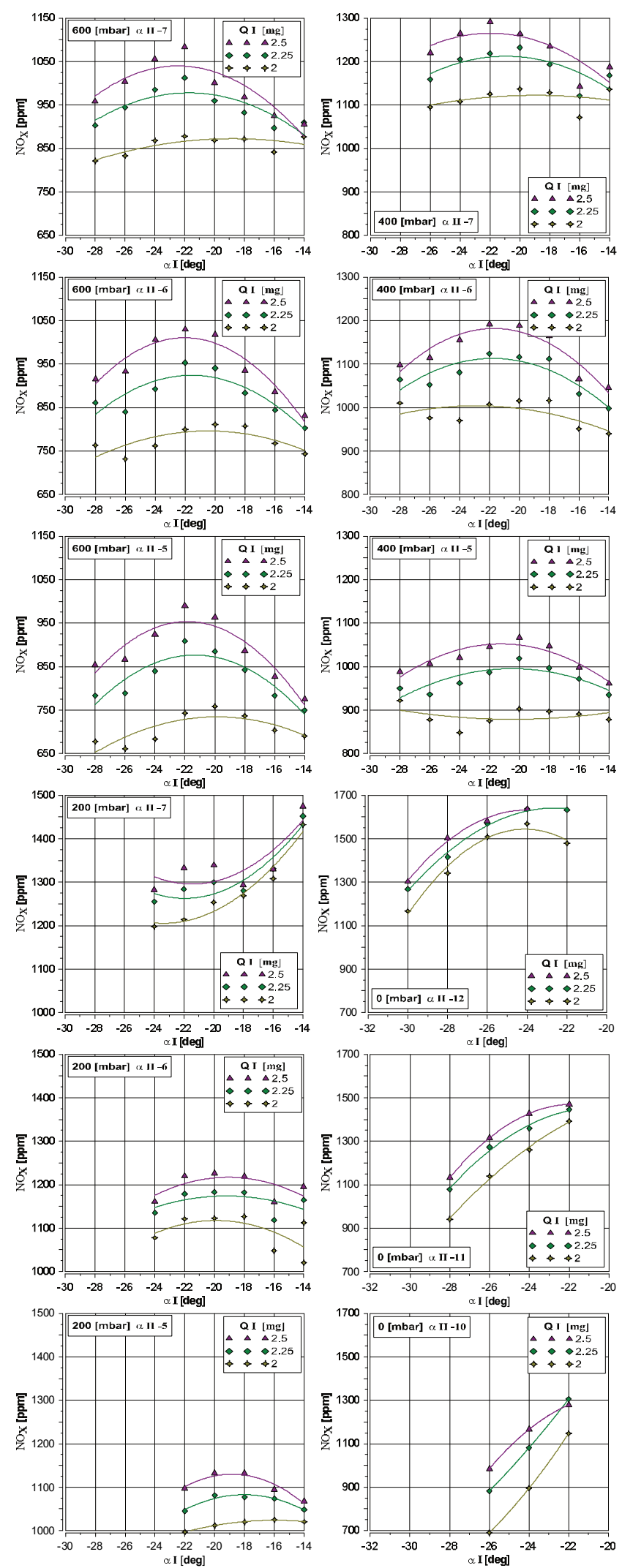

Fig. 3. Characteristics of variability of nitrogen oxides' $\left(\mathrm{NO}_{\mathrm{x}}\right)$ content in exhaust for different injection parameters of diesel fuel dose initiating ignition

- dose contributes to $\mathrm{NO}_{\mathrm{x}}$ reduction for both versions of the engine. In order to justify the first formulated conclusion, one should refer to pressure registered in the cylinder du- ring the time of the study. There is a close relationship between the combustion pressure and the $\mathrm{NO}_{\mathrm{x}}$ content inthe exhaust $[5,7,8]$. The highest dose of QI results in the highest combustion pressure and thus the highest temperature in the cylinder. A very small difference in the amount of fuel delivered in the QI dose of only 0.5 $\mathrm{mg}$ causes a clear difference in $\mathrm{NO}_{\mathrm{x}}$ concentration of about $200 \mathrm{ppm}$. The dual-fuel supply causes that this effect is more pronounced than in case of standard supply. It is connected with the course of energy release of both fuels. This means that the energy released by the dose Q1 is the sum of the diesel energy of this dose and the energy of the part of propane covered by its range. Thus, a slight increase in the pilot dose rate will translate into the release of more heat before the TDC, and this in turn into the previous combustion of the rest of the charge, the energy of which will be released by the QII dose.

The change in the $\mathrm{NO}_{\mathrm{x}}$ concentration due to the change in the injection advance angle of the QI dose also depends on the energy release type of both fuels and more precisely on the location of this process. In almost all considered cases, there is such a position of the angle of the beginning of injection of the QI dose at which the maximum concentration of this component is visible and falls on $20^{\circ}, 22^{\circ}$ C.A. before TDC. Changing this value both towards the previous and later values results in a decrease in the concentration of this component. Earlier advance injection angle for QI makes the dose go to the element of lower concentration and temperature. This leads to extend the delay of self-ignition and consequently to limit the intensity of heat generation. Further increasing the angle of the beginning of injection for QI dose will contribute to the situation at which the dose will not initiate the combustion process. So the combustion process will start after the main dose injection what will cause a considerable delay in the whole process, and the peak value of pressure and temperature will appear much later than in case when pilot dose initiates the combustion process. Such a phenomenon will contribute to lowering the concentration of $\mathrm{NO}_{\mathrm{x}}$, yet one needs to remember that such a change will entail the decrease of thermal efficiency of the engine. On the other hand, delaying the angle of the beginning of injection for QI dose up to some time also results in decreasing the concentration of $\mathrm{NO}_{\mathrm{x}}$. This mechanism is slightly different than the one described earlier. Although, injection of QI dose is realised closer to TDC and the dose takes up the combustion process, the time between the injection of pilot dose and the main dose becomes shorter.

If the time difference between the ignition initiated by the QI dose and the injection of QII dose is shortened (as a result of delaying the injection of QI dose), what effects in decreasing of maximum pressure in the combustion process, then the mechanism of this phenomenon is much dependent on the influence of the former. At the longer time difference which resulted in obtaining maximum combustion pressure when the pilot dose was injected about $20^{\circ}, 22^{\circ}$ before TDC, the time for expansion of heat generated by QI dose is longer and the same the area influenced by this dose will be bigger. So the injection of QII dose realized to the bigger area of higher temperature due to QI dose combustion will cause the inten- 
sity increase of evaporation of the fuel supplied in QII dose, shortening of self-ignition time, and consequently earlier and more intense heat generation. Moreover, at a longer time difference it is possible to mix the products of QI dose combustion with the mixture of propane and the air what may also have a positive impact on fuel oxidation supplied in QII dose. So shortening the time difference between the ignition caused by QI dose and QII dose injection one may conclude that the described mechanism is not so effective. The observed phenomenon created the basis for determining the best value of the angle of the beginning of injection of the pilot dose both considering $\mathrm{NO}_{\mathrm{x}}$ emission, thermal and general efficiency of the studied engine.

The third formulated conclusion (does not require a thorough analysis) is a result of a simple relation between maximum combustion pressure and the angle of the beginning of injection of the main dose. The change in the angle of the beginning of injection for QII dose causes clear changes in the combustion course which are reflected in form of composition changes of $\mathrm{NO}_{\mathrm{x}}$. It is worthwhile that the combustion pressure depends on the charging pressure so the highest composition of $\mathrm{NO}_{\mathrm{x}}$ should be observed for the engine charged with the highest pressure. However, this relation is different. There are few factors that may be responsible for such a relation. One of them is blowing out the cylinder. At the moment of valve overlap the cylinder is blown out with air from the intake system. The intensity of this phenomenon at the constant rotational speed and engine load, as well as constant value of angle of valve overlap depends on the value of charging pressure. It means that the higher charging pressure increases the intensity of blowing out the cylinder what translates into decreasing the temperature of combustion chamber thus improving the filling of the cylinder. As a result, the lower load temperature (substrates) may effect in the lower concentration of $\mathrm{NO}_{\mathrm{x}}$ in the exhaust.

Another factor responsible for the lower concentration of $\mathrm{NO}_{\mathrm{x}}$ for the charged engine may be slight differences in the air-fuel ratio for the different versions of charging. Both calculated and measured value of this ratio may slightly differ from the reality. The measured mass of air supplied to the engine is not the mass which takes part in the combustion process. The air supplied to the engine includes a part of the air closed in the cylinder and a part goes to the outlet system during valve coverage. Applying this proposal one can assume that with the increase of charging pressure the real air-fuel ratio will decrease. On the basis of these assumptions we need to add that the higher the intensity of blowing out the cylinder, the higher the degree of exhaust dilution with the air taking part in the blowing out process. As a consequence, registered volume concentration of the particular exhaust constituents will be lower.

\subsection{Variability characteristics of particulate matter content for different injection parameters \\ of the diesel fuel dose initiating the ignition}

Dual-fuel engine supply may considerably influence limiting the emission of particulate matter (PM) in comparison to the emission obtained for the engine supplied in a standard way what is an unquestionable advantage of the engine supplied like this $[1,8]$. The concentration of this
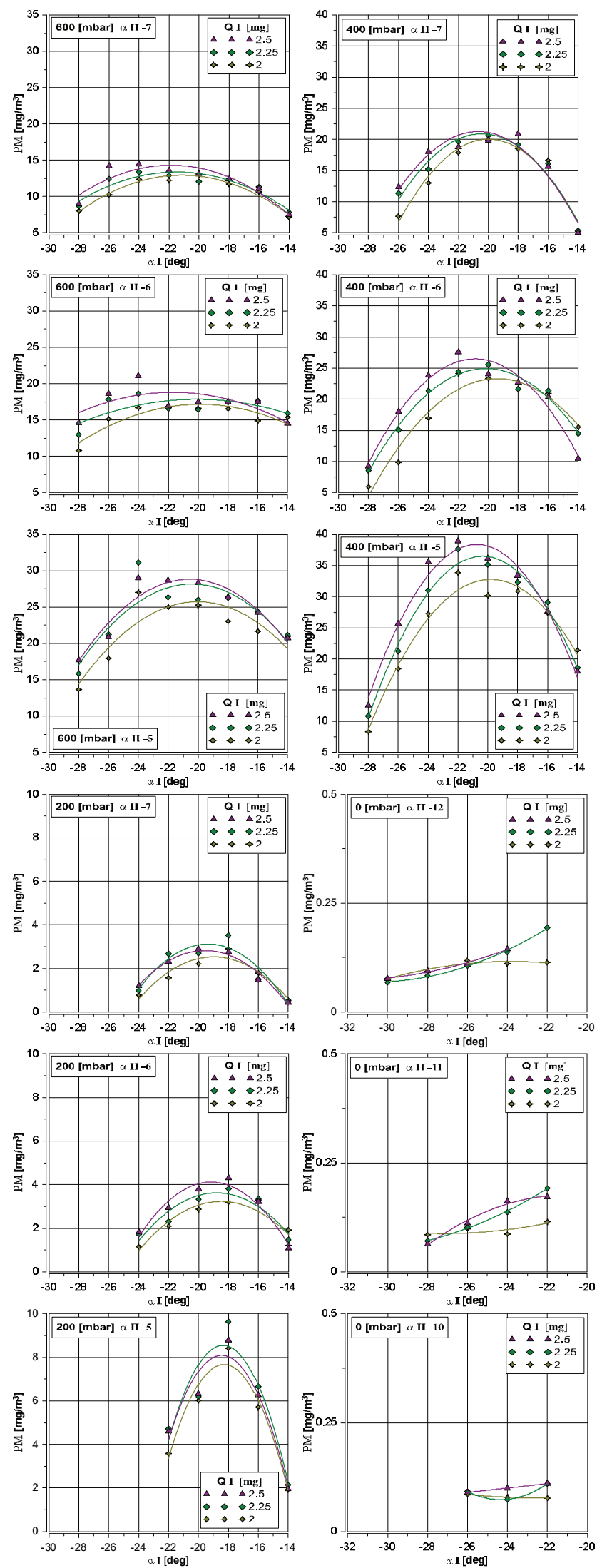

Fig. 4. Characteristics of variability of particulate matter (PM) content in exhaust for different injection parameters of diesel fuel dose initiating ignition

constituent depends above all on the type of additional fuel, as well as the contribution of this fuel in the combustion process. 
The best results are obtained by supplying the engine with gaseous fuels with a small number of carbon atoms (methane, propane, butane), with the lowest possible contribution of the ignition initiating diesel fuel dose. This means that the main fuel responsible for the emission of particulate matter is standard fuel, the full elimination of which is not possible.

The results presented above allow to formulate the following conclusions:

a) with the increase of QI diesel fuel pilot dose value the concentration of PM also increases,

b) with the increase of charging pressure the concentration of PM also increases (it reaches the smallest value in case of uncharged engine),

c) adjustment of injection advance angle of the QI dose causes the changes in PM concentration; the more delayed the injection angle of the QII, the greater the changes of PM concentration,

d) for the charged engine the delay of angle of the beginning of injection for QII dose is accompanied by the increase in PM concentration.

The nature of particulate matter emission for particular values of the angle of the beginning of injection for the QI dose is similar to the one discussed above regarding $\mathrm{NO}_{\mathrm{x}}$ emission. The maximum concentration of particulate matter corresponds to the angle of the beginning of injection for the QI dose in the range $18^{\circ}-22^{\circ} \mathrm{C}$.A. before TDC, it is also the highest for the biggest dose of QI. The most favourable mechanism for the formation of $\mathrm{NO}_{\mathrm{x}}$ and $\mathrm{PM}$ runs under the same conditions. Due to the $70 \%$ contribution of energy supplied with propane, one would expect a considerable reduction in the level of this constituent in relation to the level recorded for the diesel fuel itself. Though, for the cases with the highest charging pressure and the late angle of the beginning of injection for QII dose, i.e. $5^{\circ}, 6^{\circ}$ before TDC, the PM emission level is higher than during the standard supply. This is a consequence of the injection of the main dose into the area devoted to QI dose. This area is characterized by a higher temperature and significant depletion of oxygen. Thus, the main portion of diesel fuel given in the QII dose, reaching such an environment partially underlies the phenomenon of pyrolysis thus creating solid particles. This means that in the dual-fuel engine the in feed of pilot dose may bring about more negative consequences than during standard supply. Unlike in case of $\mathrm{NO}_{\mathrm{x}}$ emission, due to the delay of the angle of the beginning of injection for QII dose, the concentration of PM increases. This phenomenon is caused probably by the temperature drop being the result of injection delay of the main dose. Both higher pressure and temperature which accompany the earlier beginning of the injection of the QII dose aids PM reduction.

\subsection{Characteristics of variability of non-methane hydrocarbons (NMHC) and propane $\left(\mathrm{C}_{3} \mathrm{H}_{8}\right)$ for different injection parameters of diesel fuel dose initiating ignition}

Crucial, from the perspective of parameters analysis, the influence of diesel fuel injection parameters on exhaust emission was the need for registration of the concentration of two following exhaust constituents, i.e. non-methane hydrocarbons coming mainly from the diesel fuel combustion, and propane, which is the main energy source for the studied engine. Figure below presents the characteristics of content of non-methane hydrocarbons.
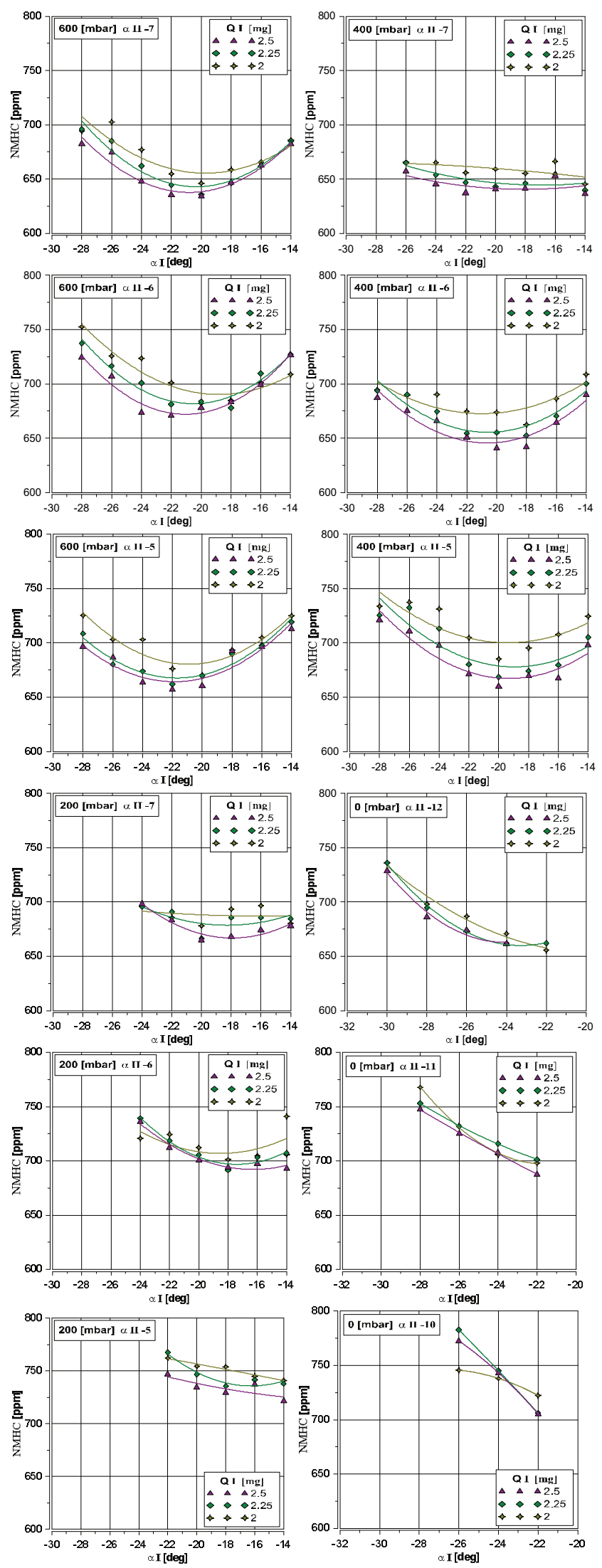

Fig. 5. Characteristics of variability of non-methane hydrocarbons (NMHC) content in the exhaust for different injection parameters of diesel fuel dose initiating ignition 
The analysis of the characteristics presented in Fig. 5 leads to formulation of the following conclusions:

a) increase in the diesel fuel pilot dose value QI is accompanied by the decrease of NMHC concentration,

b) adjustment of injection advance angle of the QI dose causes slight, about $10 \%$ changes in concentration (NMHC), and the lowest concentrations occur for the adjustment at which maximum value of combustion pressure is reached,

c) delay of injection advance angle for QII dose causes slight increase of the concentration (NMHC).

The abovementioned observations allow to conclude that the content of non-methane hydrocarbons decreases with increasing pressure and, therefore, temperatures in the combustion process. This is the effect of improving the quality of diesel fuel dose combustion.

The injected dose of QI has better conditions for the formation of a combustible mixture compared to the dose of QII. This is mainly due to the easier access to oxygen. Injection of dose QII is carried out to an area in which the oxygen content is lower due to the fact that the QI dose has been burned out.

It should be pointed out that along with the increase in the dose of QI, the dose of QII is proportionally reduced, which has been a condition for maintaining a constant amount of energy supplied with diesel fuel. This means that from the point of view of NMHC hydrocarbons emission, it is beneficial to increase the pilot dose at the expense of the main dose. This is confirmed by previous studies $[4,5,9]$. Unfortunately, the increase in the pilot dose or the elimination of the division of the diesel dose causes a clear increase in the maximum rate of pressure build-up, especially with a significant proportion of propane, which makes the work of such a powered engine impossible. Referring to the main concept of a dual-fuelled engine that concerns the largest possible contribution of additional fuel, it is essential that the energy of this fuel is used as best as possible. One of the ways to determine the quality of this energy use will be to measure the propane concentration in the exhaust. The aim of the studies was to shape the combustion process so that the concentration of propane (the main fuel) in the exhaust gas was as small as possible what has been mentioned in the introduction. The test results presented below indicate that the propane content in the engine exhaust gas is shaped differently to the NMHC component discussed above, while it resembles the $\mathrm{NO}_{\mathrm{x}}$ nitrogen oxide emission.

Since the dependence of propane emission on the diesel fuel injection parameters is the same as in the case of nitrogen oxides, the formulated conclusions are similar:

a) the increase of the pilot dose value of diesel fuel for QI is accompanied by the increase in $\mathrm{C}_{3} \mathrm{H}_{8}$ concentration,

b) adjustment of injection advance angle of the QI dose causes almost $20 \%$ changes in concentration of $\mathrm{C}_{3} \mathrm{H}_{8}$ for the charged engine and slightly bigger changes for the uncharged engine,

c) delay of injection advance angle for QII dose causes $\mathrm{C}_{3} \mathrm{H}_{8}$ reduction for both versions of the engine.

Analysing the above conclusions, and confronting them with the results characteristic to the combustion process, one can notice a clear correlation between the maximum combus- tion pressure and the maximum propane concentration. Under the same engine operating conditions (same diesel inject-
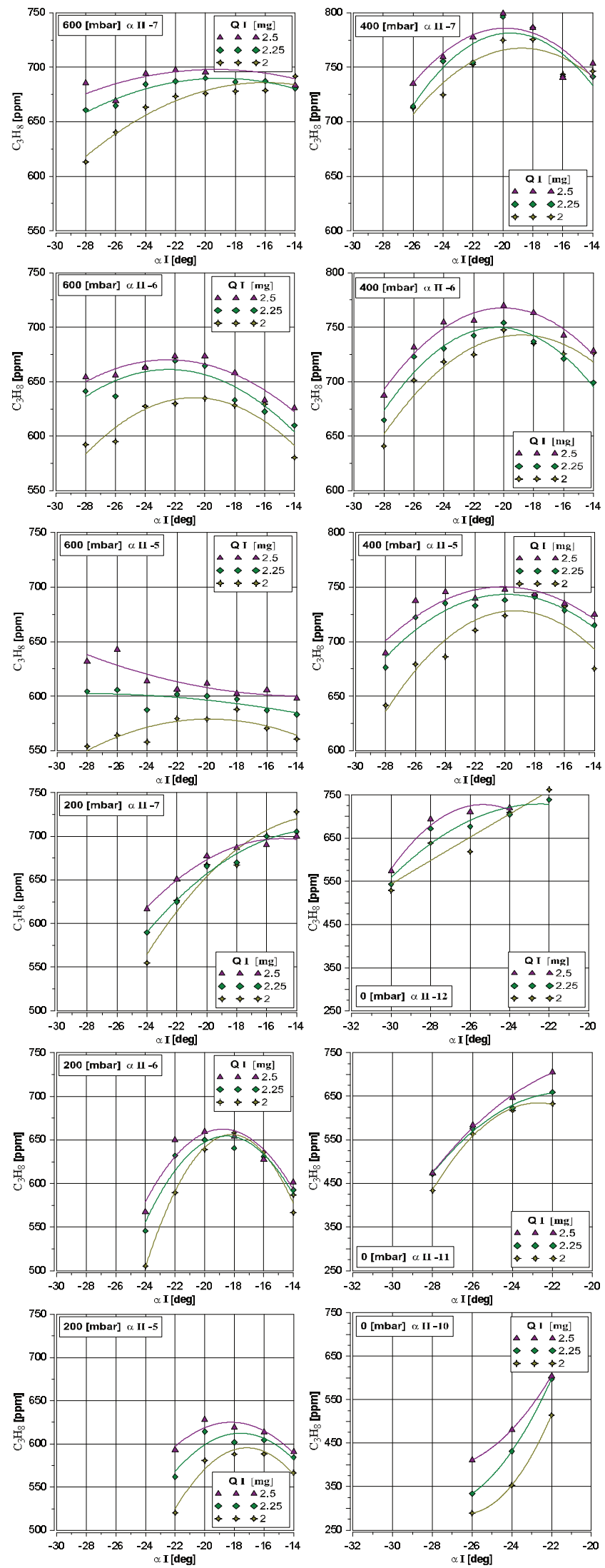

Fig. 6. Characteristics of variability of propane $\left(\mathrm{C}_{3} \mathrm{H}_{8}\right)$ content in the exhaust for different injection parameters of diesel fuel dose initiating ignition 
tion parameters, and charging pressure) the maximum propane concentration and the maximum combustion pressure are registered, while the decrease in the combustion pressure is accompanied by a drop in propane concentration.

Since the increase in propane emission depends on the increase in the QI dose volume which clearly initiates the combustion process and determines the maximum combustion pressure, it means that the QII injection is realized to the agent with a higher pressure and temperature, which may be the reason for reducing the range of the diesel fuel stream. Thus, the mixture of propane and air away from the central part of the combustion chamber in which the diesel dose is injected is not ignited, which is the main reason for the increase in propane concentration in the exhaust. It should be emphasized that the dose of QII and its range decrease with the increase of QI dose which additionally intensifies this phenomenon. However, increasing concentration of propane in the exhaust does not translate into a decrease in thermal or general efficiency of the engine. This means that the efficiency of the studied engine depends more on the combustion process being shaped by the diesel fuel injection parameters than the propane combustion efficiency measured by the emission of this component. It should also be emphasized that in part the emissions of this component are caused by the escape effect of the load during the valve overlap [6]. Despite the synchronization of the propane injector opening time with the time the cylinder is filled with air, it is very difficult to completely avoid the escape of the load. As shown in the previous studies, at the end of filling the cylinder it is possible that the load regresses to the intake manifold, which in turn takes part in blowing out the cylinder.

\section{Conclusions}

The possibilities of shaping the combustion process provided by the modern charging system of common rail type contribute to elimination of many limitations resulting from introducing CI charging, especially with the significant contribution of the additional fuel. It is crucial that the choice of diesel fuel injection parameters, namely division of the dose, volume of both pilot and main dose as well as the angle of the beginning of injection depended both on the share of the main fuel, its properties and parameters of engine work, namely: charging pressure, load and rotational speed. It is connected to the need of performing number of regulation characteristics of the engine fuelled this way which would take the aforementioned parameters into account. It is necessary though to determine the criterion for which the adjustment of diesel fuel injection parameters will be realized. As the results of the studies presented in this article have shown, we will need a compromise, since the benefits resulting from improving emission of exhaust composition thanks to the adjustment of diesel oil injection parameters do not equal efficiency improvement of the studied engine. In spite of number of difficulties that introducing a dual-fuel CI engine entails, there are objective benefits in favour of continuation of the studies whose consequence will be more efficient, cheaper in exploitation and environment-friendly engine.

\section{Nomenclature}

CI compression ignition

LPG liquified petrolum gas

DF diesel fuel
TDC top dead center

QI diesel oil pilot dose

QII diesel oil main dose

\section{Bibliography}

[1] DEO RAJ, T., GOPAL P. SINHA. Performance and emission study of LPG diesel dual fuel engine. Int. J. Eng. Adv. Technol. (IJEAT). 2014, 3(3).

[2] GARBALA, K., PIEKARSKI, W., ANDRZEJEWSKA, S., WITASZEK, K. Analysis of operating parameters and indicators of a compression ignition engine fuelled with LPG. Scientific Journal of Silesian University of Technology. Series Transport. 2016, 93, 13-22.

[3] PAWLAK, G. The concept of a dual fuel highly efficient internal combustion engine. SAE Technical Paper. 2010. DOI:10.4271/2010-01-1480.

[4] POLK, A.C., GIBSON, C.M., SHOEMAKER, N.T. et al. Analysis of ignition behavior in a turbocharged direct injection dual fuel engine using propane and methane as primary fuels. American Society of Mechanical Engineers. DOI:10.1115/ ICEF2011-60080.

[5] SUNDAR, R.K., KALYAN, K.S., MOSTAFA, S.R. The effect of injection parameters and boost pressure on dieselpropane dual fuel low temperature combustion in a single-

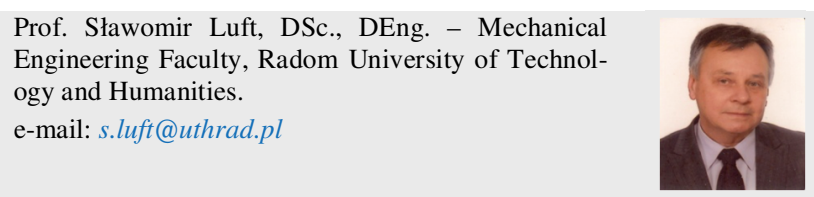

cylinder research engine. Fuel. DOI:10.1016/j.fuel.2016.07. 042.

[6] SKRZEK, T. Assessment of the effect of gaseous fuel delivery mode on thermal efficiency and fuel losses during the valve overlap period in a dual-fuel compression ignition engine. IOP Conf. Series: Materials Science and Engineering. 148 012086 DOI:10.1088/1757-899X/148/1/012086, 2016.

[7] SKRZEK, T. Effect of the diesel fuel dose division and the injection angle on operating parameters of a dual-fuel compression ignition engine. Combustion Engines. 2015, 3(162). DOI:10.19206/CE-2017-319.

[8] STELMASIAK, Z., MATYJASIK, M. Exhaust emissions of dual fuel self-ignition engine with divided initial dose. Combustion Engines. 2013, 154(3).

[9] YOUSEFI, A., BIROUK, M. An investigation of multiinjection strategies for a dual-fuel pilot diesel ignition engine at low load. Journal of Energy Resources Technology. 2016, 139(1). DOI: 10.1115/1.4033707.

Tomasz Skrzek, DEng. - Mechanical Engineering Faculty, Radom University of Technology and Humanities.

e-mail: t.skrzek@uthrad.pl 